\title{
MULTIDISCIPLINARY APPROACH IN THE PREVENTION AND TREATMENT OF COMPLICATIONS OF TRANSCATHETER ARTERIAL CHEMOEMBOLIZATION OF LIVER ARTERIES
}

\author{
Elena Zvezdkina ${ }^{*}$, Dmitry Lebedev ${ }^{2}$, Anna Kedrova ${ }^{2}$, \\ Yulia Stepanova3, Dmitry Astakhov²,4, Dmitry Panchenkov²,4
}

\begin{abstract}
${ }^{1}$ State Scientific Center of Laser Medicine named after O.K. Skobelkin of the Federal Medical and Biological Agency of Russia, Moscow, Russian Federation

${ }^{2}$ Federal Research Clinical Center for Specialized Types of Health Care and Medical Technologies of Federal Medical and Biology Agency, Moscow, Russian Federation

3Vishnevsky National Medical Research Center for Surgery, Moscow, Russian Federation 4Evdokimov Moscow State University of Medicine and Dentistry, Moscow, Russian Federation
\end{abstract}

\begin{abstract}
The aim of the study is to assess the role of the surgical technique and liver response in the development of complications after transcatheter arterial chemoembolization of liver arteries using drug-eluting beads (DEB-TACE). The study included 34 patients who underwent 52 DEB-TACE with drug-saturated microspheres in 2014 - 202O. CT and MRI were performed for follow-up and if complications were suspected. The modification of the surgical technique made it possible to avoid complications from the vascular wall and non-target embolization. Stages of complications from the bile ducts can be diagnosed on CT and MRI. This can help slow down the further development of the process. Separate patients at risk groups based on previous treatment prevent of developing severe complications.
\end{abstract}

Key words: Oncology, chemoembolization of liver arteries, drug-eluting beads, microsphere, Computed Tomography (CT), Magnetic Resonance Imaging (MRI)

\section{INTRODUCTION}

Until recently, treatment options for unresectable primary and metastatic liver cancer were extremely limited. However, now there are results of studies devoted to a new method of treatment of this pathology such as transcatheter arterial chemoembolization of liver arteries using drug-eluting beads (DEB-TACE) [1, 2 , 3]. The method is based on the delivery of a chemotherapy drug directly to the tumor in a polymer microsphere. In addition to the drug effect, the method causes tumor ischemia due to the ability of microspheres to increase in volume and cause arterial occlusion. Since DEB-TACE is a surgical endovascular intervention, it carries the following risks [4]: 1) dissection of the vessel wall and its rupture; 2) spasm and / or acute thrombosis of the vessel at the access site or in the area of operation; 2) non-target embolization with the development of ischemic damage to adjacent organs and tissues; 3) the formation of arterioportal fistulas. Much attention is paid to the technique of endovascular access and the use of micro-catheters for adequate transportation of microspheres to the target focus and prevention of these situations [5]. However, the number and severity of complications and their dependence on the technical aspects of the intervention have been little studied.

In addition, transcatheter arterial chemoembolization of the hepatic arteries has a chemical and ischemic effect on the bile ducts, which is expressed by the development of postembolization syndrome including transient abdominal pain and fever. There is still no consensus on whether this condition is a complication or a natural consequence of manipulation. In addition, severe reactions $[6,7]$ of the liver to acute disturbance of arterial blood supply after TACE have been described: bilomas, acute parenchymal infarction, portal vein obliteration. Understanding the different types of complications caused by DEB-TACE is important for radiologists, oncologists, and surgeons to predict them and identify risk groups [8].

\section{AIM}

The aim of the study is to assess the role of the technique of performing DEB-TACE in the development of complications, to determine the number and diagnostic criteria of complications of TACE from the liver, to identify risk groups for the development of complications.

\section{MATERIAL AND METHODS}

\subsection{Patients}

The study included 34 patients who underwent 52 DEB-TACE with drug-saturated microspheres in 2014 2020. The follow-up period ranged from 6 months to 5 
E. Zvezdkina et al., Multidisciplinary approach in the prevention and treatment..., RAD Conf. Proc., vol. 4, 2020, 66-68

years. Computed Tomography (CT) and Magnetic Resonance Imaging (MRI) with bolus contrast enhancement were performed before DEB-TACE, after 8 weeks, 16 weeks, then every 3 months. If complications were suspected, CT and MRI were performed according to indications, the results were compared with clinical and laboratory data.

The distribution according to the localization of the primary tumor was: colon $(n=14)$, pancreas $(n=5)$, stomach $(n=2)$, prostate $(n=2)$, lung $(n=2)$, hepatocellular cancer $(n=2)$, cancer of the small intestine, rectum, ovaries, uterine body, breast, oropharynx, cholangiocarcinoma $(n=1$, respectively). According to the histological type of metastases, adenocarcinoma was found in 23 cases and neuroendocrine cancer in 8 cases. The studied patients had the following types of liver damage: bilobar multiple focal liver damage $(n=27)$, a single large focus $(n=4)$, multiple tumors with an infiltrative growth pattern along the bile ducts $(n=3)$ (parabiliary metastases of colorectal cancer and cholangiocarcinoma).

\subsection{Chemoembolization of liver arteries}

We used microspheres HepaSphere ${ }^{\mathrm{TM}}$ Microspheres with a diameter of 50-100 $\mu \mathrm{m}$ with the possibility of drug saturation up to a working diameter of $200-400 \mu \mathrm{m}$. This allowed to perform sequential superselective catheterization of targeted tumor arteries with a micro-catheter and the introduction of a sufficient amount of drug-saturated microspheres with doxorubicin or irinotecan until the control point was reached.

The right femoral artery $(n=9)$, right radial artery $(n=25)$, left radial artery $(n=17)$, and left ulnar artery $(n=1)$ were used to provide access to the arterial vascular bed. Prior to DEB-TACE, angiography was performed to locate all the feeding arteries of a tumor. This data was also compared with the localization of lesions obtained from non-invasive imaging (CT and MRI), which determined the choice of arteries for chemoembolization. After that a micro-catheter were advanced superselectively into the feeding arteries of the tumor.

Control arteriography was performed in all patients to confirm occlusion of tumor arteries with drugsaturated microspheres and to complete chemoembolization.

The procedure for the introduction of microspheres with a cytostatic was carried out under the control of the general condition of the patient, including monitoring of heart rate, pulse and blood pressure. All patients were sedated before surgery.

Initially, one procedure was planned, repeated DEB-TACE were performed as the tumor process progressed.

\section{RESULTS AND DISCUSSIONS \\ 4.1. The role of surgical technique in the development of complications}

DEB-TACE was performed once in 20 patients ( 5 men and 15 women). 10 patients ( 5 men and 5 women) required a second procedure, while the duration from the first DEB-TACE ranged from 2.07 to 12.37 months (on average $7.06 \pm 3.7$ months). 3 men and 1 woman underwent the third DEB-TACE: the period from the first DEB-TACE was 9 months, 11 months, 29 months, and from the second DEB-TACE - 4, 6, 8 months, respectively.

Table 1. Patient categories and duration of postembolization syndrome after DEB-TACE

\begin{tabular}{|c|c|c|c|}
\hline & & $\begin{array}{c}\text { Mean age, } \\
\text { years }\end{array}$ & $\begin{array}{c}\text { Postembolization } \\
\text { syndrome, day }\end{array}$ \\
\hline \multirow{2}{*}{$\begin{array}{c}\text { 1st } \\
\text { DEB- } \\
\text { TACE }\end{array}$} & $\begin{array}{l}\text { men } \\
\mathrm{n}=5\end{array}$ & $54.7 \pm 3.5$ & $1.25 \pm 0.04$ \\
\hline & $\begin{array}{c}\text { women } \\
\mathrm{n}=15\end{array}$ & $55.63 \pm 5.5$ & $1.15 \pm 0.08$ \\
\hline \multirow{2}{*}{$\begin{array}{l}\text { 2nd } \\
\text { DEB- } \\
\text { TACE }\end{array}$} & $\begin{array}{l}\text { men } \\
\mathrm{n}=5\end{array}$ & $60 \pm 1.5$ & $1.5 \pm 0.03$ \\
\hline & $\begin{array}{c}\text { women } \\
\mathrm{n}=5\end{array}$ & $61.96 \pm 9.5$ & $1.11 \pm 0.09$ \\
\hline \multirow{2}{*}{$\begin{array}{c}\text { 3rd } \\
\text { DEB- } \\
\text { TACE }\end{array}$} & $\begin{array}{c}\text { men } \\
\mathrm{n}=3\end{array}$ & $69 \pm 6.7$ & $1.1 \pm 0.05$ \\
\hline & $\begin{array}{c}\text { women } \\
n=1\end{array}$ & 67 & 1.5 \\
\hline
\end{tabular}

In accordance with our data (Table 1), postembolization syndrome was observed in all cases. Its duration was approximately the same in all groups of patients.

Intraoperative complications such as spasm of arteries, their dissection, occlusion, rupture have never been encountered in DEB-TACE using micro-catheter technique.

In the presence of pronounced collaterals and arteriovenous fistulas, the use of a micro-catheter made it possible to avoid non-target embolization (Fig. 1).

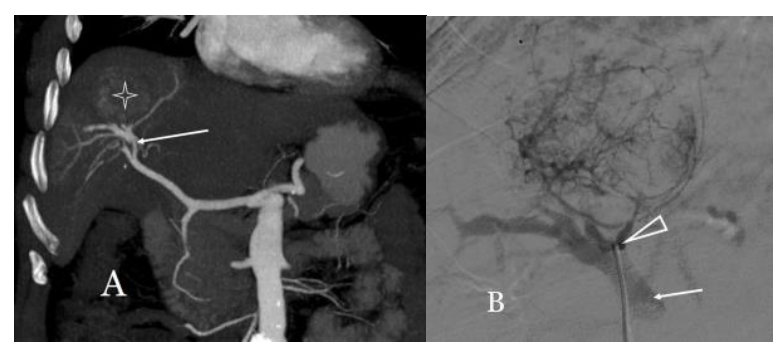

Figure 1. A: CT imagine demonstrate hepatocellular cancer (asterisk) surrounded by arteriovenous fistulas (arrow).

B: arteriography shows micro-catheter (arrowhead) in the tumor artery distal to arteriovenous fistulas (arrow).

\subsection{The role of liver reaction and previous treatment in the development of complications}

Alanine transaminase (ALT), aspartate transaminase (AST) levels were determined to assess liver response to DEB-TACE. They returned to preoperative values within 1-2 months after most of the operations performed $(n=32)$. In 14 cases, this was 
not noted, while the physical health of the patients suffered (nausea, weakness, loss of appetite, fever).

6 patients from this group underwent MRI, 8 patients underwent CT at 5-6 weeks after surgery. According to the imaging, 9 patients had cholangitis, which manifested as patterns of periductal infiltration and local dilatation of the intrahepatic bile ducts. In 6 cases, the revealed changes regressed after hepatoprotective therapy and the physical health of the patients improved.

In one case multiple bilomas were developed, which persisted for 4 months (the patient died from generalization of the oncological process).

One patient appeared multiple bilomas and abscesses along the bile ducts, which regressed for 3 months of nonsurgical treatment (the follow-up period for the patient was 11 months).

In 1 case, necrosis of the liver parenchyma formed at the site of cholangitis, which was infected and required surgical treatment (the follow-up period was 4 months, the patient died from generalization of the oncological process). All 3 patients had previous reconstructive operations on the bile ducts, with cholangiostomy and common bile duct stent.

\section{CONCLUSION}

1) Drug-eluting beads allowed modify the surgical approach and use micro-catheters, which made it possible to avoid complications from the vascular wall;

2) the use of a micro-catheter made it possible to accurately deliver the chemotherapy drug to the tumor and avoid non-target embolization;

3) postembolization syndrome should not be attributed to complications of DEB-TACE;

4) DEB-TACE can cause cholangitis, which requires monitoring of the liver condition;

5) complications from the bile ducts have stages that can be diagnosed on CT and MRI and prevent the development of severe conditions;

6) patients with previous operations on the bile ducts are at risk group of developing severe complications and require the careful attention of all specialists.

\section{REFERENCES}

1. R.J. Lewandowski, M.F. Mulcahy, L.M. Kulik et al. "Chemoembolization for Hepatocellular Carcinoma" Radiology, vol. 255, no. 3, pp. 955-965, Jun. 2010. https://doi.org/10.1148/radiol.10091473 PMID: 20501733

2. N. Kennoki, T. Saguchi, T. Sano, Y. Takara, T. Moriya et al. "Long-term Histopathologic Follow-up of a Spherical Embolic Agent; Observation of the Transvascular Migration of HepaSphere ${ }^{\mathrm{TM}}$ ", BJR Case Rep, Jun 25 (5), 1, 20180066, 2019.

https://doi.org/10.1259/bjrcr.20180066

3. Y. Xiao-Dan, Y. Zuguo, Z. Hang et al. "Radiological biomarkers for assessing response to locoregional therapies in hepatocellular carcinoma: From morphological to functional imaging", Oncology reports, vol. 37, no. 3, pp. 1337-1346, 2017. http://doi.org/10.3892/or.2017.5420

4. J. Chung, J-S. Yu, J. H. Kim et al. "Haemodynamic events and localised parenchymal changes following transcatheter arterial chemoembolisation for hepatic malignancy: interpretation of imaging findings". The British Journal of Radiology, no. 83, pp. 71-81, 2010. https://doi.org/10.3892/mc0.2017.1235

5. А.М. Бабунашвили, Д.П. Дундуа, З.А. Кавтеладзе, Д.С. Карташов, Переход с трансбедренного на трансрадиальный доступ в практике интервенционной кардиологии: сможет ли стать трансрадиальный доступ методом выбора? // Международный журнал интервенционной кардиоангиологии, - 2005, - №7, - С. 73 [A.M. Babunashvili, D.P. Dundua, Z.A. Kavteladze, D.S. Kartashov, The transition from transfemoral to transradial access in the practice of interventional cardiology: can transradial access be the method of choice? // International Journal of Interventional Cardioangiology, 2005 (7):73. (In Russian)]

6. S. Chittapuram, B. Ramesh, S. Malay, "Biliary Tract Anatomy and its Relationship with Venous Drainage", Journal of Clinical and Experimental Hepatology, no. 1, pp. 18-26, 2014. https://doi.org/10.1016/j.jceh.2013.05.002 PMCID: PMC4244820

7. B. Guiu et al. "Liver/biliary injuries following chemoembolisation of endocrine tumours and hepatocellular carcinoma: Lipiodol vs. drug-eluting beads". Journal of hepatology, vol. 56, no 3 , pp. 609-617, 2012.

https://doi.org/10.1016/j.jhep.2011.09.012 PMID: 22027582

8. J. C. Spina, M. Ulla, E.L. Yeyati, M.C. Kucharczyk, H. Irusta, J.L. Savluk et al. "MDCT findings after hepatic chemoembolization with DC-beads: What the radiologist needs to know", Abdominal Imaging, vol. 38, pp. 778-784, 2013.

http://doi.org/10.1007/s00261-012-9963-6 